\title{
COVID-19 salgınının diş hekimleri üzerinde yarattığı gelecek kaygısı ve stresin değerlendirilmesi
}

\author{
Evaluation of future anxiety and stress levels caused by COVID-19 on dentists \\ Müberra Kulu, Filiz Özsoy, Esra Bihter Gürler, Dilek Özbeyli
}

Özet

Amaç: Bu çalışmanın amacı yeni tip korona virüs (COVID-19) hastalığının diş hekimleri üzerinde yarattığı gelecek kaygısı ve stres düzeyini incelemektir.

Gereç ve yöntem: Çalışma "Google Form" aracılığı ile oluşturulan formlar aracılığı ile online olarak yürütüldü. Ülkemizde yaşayan özel ve/veya kamu kurumlarında diş hekimi olarak çalışan, 25-65 yaş arası kişiler çalışmaya dahil edildi. Tüm katılımcılara; sosyodemografik ve klinik değerlendirme formu, Algılanan Stres Ölçeği (ASÖ) ve araştırmacılar tarafından oluşturulan gelecek ile ilgili kaygı düzeyini değerlendiren gelecek kaygısı formu uygulandı.

Bulgular: Çalışmamıza 228 diş hekimi dahil edildi. 118 kişi (\%52) kadın ve 110 kişi (\%48) erkek idi. Katılımcılardan 161 kişi $(\% 70)$ evli iken 53 kişi $(\% 23,24)$ bekardı. Bu kişilerden 77 kişi $(\% 33,77)$ 25-35 yaş aralığında, 74 kişi

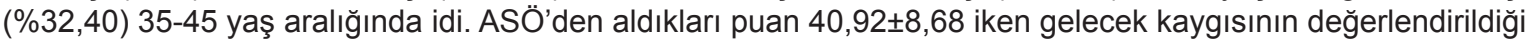
formdan ise $114,18 \pm 33,19$ olarak hesap edildi.

Sonuç: Bulgularımız diş hekimlerinde COVID-19'a bağlı yüksek stres düzeyini ve gelecek kaygısını işaret etmektedir. Bu nedenle, salgın sürecinde diş hekimlerinin stres düzeylerini ve kaygılarını azaltacak önlemlerin alınması önerilmektedir.

Anahtar kelimeler: Diş hekimliği, COVID 19, gelecek kaygısı, algılanan stres.

Kulu M, Özsoy F, Gürler EB, Özbeyli D. COVID-19 salgınının diş hekimleri üzerinde yarattığı gelecek kaygısı ve stresin değerlendirilmesi. Pam Tıp Derg 2021;14:103-112.

\begin{abstract}
Purpose: The aim of this study is to investigate the future anxiety and stress level created by dentists on the novel coronavirus (COVID-19) pandemic.

Material and methods: The study was carried out online using the forms created by "Google Form". People aged 25-65, working as dentists in private and/or public institutions living in our country, were included in the study. To all participants; sociodemographic and clinical evaluation form, Perceived Stress Scale (PSS) and future anxiety form evaluating the future anxiety level created by the researchers were applied.

Results: In total 228 dentists were included in our study. 118 people (52\%) were female and 110 people (48\%) were men. While 161 people $(70 \%)$ of the participants were married, 53 people $(23.24 \%)$ were single. Our study participants $77(33.77 \%)$ were between the ages of $25-35$ and 74 people (32.40\%) were in the 35-45 age range. While the score they received from PSS is $40.92 \pm 8.68,114.18 \pm 33.19$ was calculated from the form where future anxiety was evaluated.

Conclusions: Our findings point to the high stress level and future anxiety due to COVID-19 in dentists. For this reason, it is recommended to take measures to reduce the stress levels and anxiety of dentists during the epidemic process.
\end{abstract}

Key words: Dentistry, COVID 19, future anxiety, perceived stress.

Kulu M, Ozsoy F, Gurler EB, Ozbeyli D. Evaluation of future anxiety and stress levels caused by COVID-19 on dentists. Pam Med J 2021;14:103-112.

Müberra Kulu, Uzm. Dr. Tokat Ruh Sağlığı ve Hastalıkları Hastanesi, Psikiyatri Kliniği, Tokat, Türkiye, e-posta: muberrakilic@yahoo.com (orcid. org/0000-0002-1402-2388)

Filiz Özsoy, Uzm. Dr. Tokat Devlet Hastanesi, Psikiyatri Kliniği, Tokat, Türkiye, e-posta: flzkoseoglu82@gmail.com (orcid.org/0000-000251988827) (Sorumlu Yazar)

Esra Bihter Gürler, Dr. Öğr. Üye. Atlas Üniversitesi, Diş Hekimliği Fakültesi, İstanbul, Türkiye, e-posta: ebgurler@gmail.com (orcid.org/00000001-8259-521X)

Dilek Özbeyli, Dr. Öğr. Üye. Marmara Üniversitesi, Tıp Fakültesi Tıbbi Fizyoloji Anabilim Dalı, İstanbul, Türkiye, e-posta: dilekozbeyli@yahoo. com (orcid.org/0000-0002-4141-6913) 


\section{Giriş}

Korona virüs hastalığı 2019 (COVID-19); Çin Hubei Eyaleti başkenti Wuhan'dan başlayıp tüm dünyaya yayılan bir grup akut solunum yolu enfeksiyonu olarak tanımlanmaktadır [1, 2]. 11/03/2020 tarihinde virüs tüm dünyada yayıldığı için Dünya Sağlık Örgütü (DSÖ) tarafından "küresel salgın" olarak ilan edilmiştir [3]. Tüm dünyada son vaka sayısı 23/06/2020 tarihi itibari ile; 8.993.659 ve COVID-19'a bağlı ölü sayısı 469.587 olarak bildirilmiştir [4]. Ülkemizde ilk vaka 10/03/2020 tarihinde görülmüştür ve 29/06/2020 tarihi itibari ile de yeni vaka ve ölüm sayısı 1.268 ve 27 olarak tespit edilmiştir [5]. Etiyolojisi tam olarak bilinmeyen COVID-19 hastalığı; soğuk algınlığından, Şiddetli Akut Solunum Sendromu (SARS) ve Orta Doğu Solunum Sendromu (MERS-CoV) olarak bilinen çeşitli hastalıklara neden olabilen geniş bir ailedir [6].

COVID-19 salgını; insanların günlük yaşam aktivitelerini, davranışlarını, alışkanlıklarını ve psikolojilerini olumsuz yönde etkilemiştir [7]. Benzeri görülmemiş böyle bir hastalıkta insanların psikolojik ve duygusal sıkıntılarını tahmin edebilmek oldukça zordur. Literatürde küresel salgınlar hakkında pek çok çalışma bulunmaktadır. [6-12]. Çin'de yapılan bir çalışma stres, belirsizlik korkusu, depresif semptomlar ve gelecek kaygısına artmış alkol ve tütün tüketiminin eşlik ettiğini ortaya koymuştur. [8]. Bir başka çalışmadaysa 1.210 sağlık çalışanı olmayan katılımcıya depresyon, kaygı, stres skalası uygulanmıştır. Katılımcıların $\% 16,5^{\prime} \mathrm{i}$ orta şiddette depresif belirtiler gösterir iken, $\% 28,8$ 'i orta şiddette kaygı belirtileri, $\% 8,1^{\prime} \mathrm{i}$ ise orta şiddette stres düzeylerine ulaştığını bildirmiştir [9]. Ülkemizde yapılan bir çalışmada ise; 159 sağlık çalışanı dışı toplumsal örneklem değerlendirilmiştir. Kadınların \%23,6'sının depresyon için, \%45,1 >inin ise kaygı için kesme noktasının üzerinde puan aldığı tespit edilmiştir. Tıbbi geçmişinde psikiyatrik tedavi alımı olan ve medikal tedavi almasını gerektirir tıbbi hastalığı olan kişilerin kaygılarının daha yüksek olduğu da saptanmıştır [13]. İncelenen bu çalışmalar meslek kollarına ayrılmadan toplum üzerinde yapılmıştır. Çin'de sağlık çalışanlarında yapılan bir çalışmada ise; kadınların ve birinci basamak sağlık çalışanlarının hastalıktan olumsuz etkilendiği ve psikolojik olarak desteğe intiyaç duyabileceği rapor edilmiştir [14]. Ülkemizde doktorlarla yürütülen bir araştırmada; kadın cinsiyet, bekar, daha az iş deneyimine sahip olma ve sahada çalışma ile yüksek kaygı ve depresyon düzeylerinin ilişkili olduğu bildirilmiştir [15]. Yine ülkemizde diş hekimliği fakültesi öğrencileri üzerinde yapılan bir çalışmada; $\% 81,1$ oran ile öğrencilerin yüz yüze eğitimten korktuğu ve dörtte birinde meslek değiştirme fikri oluştuğu saptanmıştır. Aynı çalışmada meslek değiştirme fikri olan öğrencilerin sürekli kaygı düzeylerinin çok daha yüksek olduğu da görülmüştür [16].

COVID-19'un damlacık enfeksiyonu olduğu bilinmektedir. $\mathrm{Bu}$ durum enfeksiyona maruz kalma ve bulaşı yayma açısından birinci derece risk grubunda değerlendirilen diş hekimlerinde COVID-19 salgınının stres düzeylerini arttıracağı hipotezi kurulmuştur. İkincil olarak hem birinci derece risk grubunda olmaları hem de stres düzeylerinin artması ile diş hekimlerinin gelecek kaygılarının da yükseleceği varsayılmaktadır. Tüm bu bilgiler ışı̆ıında, çalışmamızda COVID-19 salgınının yarattığı stres ve gelecek kaygısı seviyelerini araştırmak amaçlanmıştır.

\section{Gereç ve yöntem}

T.C. Sağlık Bakanlığı 2020-05-16T15_47_53 numaralı izni sonrası, Marmara Üniversitesi Tıp Fakültesi KlinikAraştırmalar Etik Kurulu'ndan etik onayı alındı. Çalışma Helsinki Deklarasyonu'na uygun şekilde online olarak yürütüldü.

Çalışmaya; Türkiye'de yaşayan ve özel ve/ veya kamu kurumlarında diş hekimi olarak çalışan, 25-65 yaş arası kişiler dahil edilmiştir. Gönüllü olan, elektronik formları doldurup onaylayan kişiler çalışmaya alınmıştır. Genel durum düşüklüğü olan, medikal tedavi almasını gerektirir kronik hastalıkları olan kişiler, psikiyatrik tedavi alımı olduğunu bildiren katılımcılar ile çalışmaya katılmak istemeyen kişiler çalışma dışı bırakılmıştır. Tüm katılımcılara; sosyodemografik ve klinik değerlendirme formu, Algılanan Stres Ölçeği (ASÖ) ve araştırmacılar tarafından oluşturulan gelecek kaygısı ile ilgili sorular içeren bir form uygulanmıştır. Katılımcılara uygulanan bu anketler araştırmacılar tarafından "Google Form" kullanılarak ard arda sorular şeklinde bir araya getirilmiştir. Hazırlanan formlar elektronik posta yolu ile online olarak katılımcılara gönderilmiştir. 


\section{Veri toplama araçları}

Sosyodemografik ve klinik değerlendirme formu: Çalışmanın amaçları ve literatür incelenmesi doğrultusunda araştırmacılar tarafından hazırlanmıştır. Yaş, medeni durum, eğitim durumu, yaşanılan yer, çalışma durumu, kaç yıldır diş hekimi olarak çalıştığı, ekonomik durum gibi demografik verileri içermektedir. Demografik verilere ek olarak tedavi almasını gerektirir tıbbi hastalığı ve psikiyatrik hastalığı olup olmadığı ve alkol/sigara kullanımı olup olmadığı gibi klinik değerlendirme sorularını içermektedir.

Algılanan Stres Ölçeği (ASÖ): Cohen, Kamarck ve Mermelstein tarafından geliştirilmiştir. Toplam 14 maddeden oluşan, öz bildirim ölçeğidir. Ölçek; "geçen ay; beklenmedik bir şeylerin olması nedeniyle ne sıklıkta rahatsızlık duydunuz", "hayatınızdaki önemli şeyleri kontrol edemediğinizi ne sıklıkta hissettiniz", "kendinizi ne sıklıkta sinirli ve stresli hissettiniz", "ne sıklıkta yapmanız gereken şeylerle başa çıkamadığınızı fark ettiniz", "kendinizi ne sıklıkta başarmak zorunda olduğunuz şeyleri düşünürken buldunuz", "ne sıklıkta kontrolünüz dışında gelişen olaylar yüzünden öfkelendiniz" ve "ne sıklıkta problemlerin üstesinden gelemeyeceğiniz kadar biriktiğini hissettiniz" gibi stresi değerlediren sorular içermektedir. Ek olarak "geçen ay, ne sıklıkta zamanınızı nasıl kullanacağınızı kontrol edebildiniz", "ne sıklıkta gündelik zorlukların üstesinden başarıyla geldiniz", "hayatınızda ortaya çıkan önemli değişikliklerle etkili bir şekilde başa çıktığınızı ne sıklıkta hissettiniz", "kişisel sorunlarınızı ele alma yeteneğinize ne sıklıkta güven duydunuz", "her şeyin yolunda gittiğini ne sıklıkta hissettiniz", "hayatınızdaki zorlukları ne sıklıkta kontrol edebildiniz" ve "ne sıklıkta her şeyin üstesinden geldiğinizi hissettiniz" gibi ters hesaplanan 7 soru da bulunmaktadır. Ölçeğin hesaplanan kesme puanı olmamakla birlikte, alınan yüksek puanlar algılanan stres düzeyinin fazla olduğuna işaret etmektedir. Türkçe geçerlik ve güvenilirlik çalışmasını Eskin ve ark. [17] yapmıştır (Ek 1).

Gelecek Kaygısı Formu: İlkkezZaleski[18] tarafından geliştirilmiş olan skala çalışmacılar tarafından COVID-19'a uyarlanmıştır. Hem salgın hastalığına karşı hem de gelecek ile ilgili hissedilen kaygı düzeyini değerlendirmek amacı ile; "COVID-19 ile kontamine olmaktan korkuyorum", "hastamı kontamine etmekten korkuyorum", "aileme bulaştırmaktan korkuyorum" gibi sorulara ek olarak "gelecekle ilgili plan yapmaktan korkuyorum", "gelecek aylar ne getirecek korkuyorum", "geleceğim çok belirsiz", "gelecekle ilgili plan yapmaktan, geleceği düşünmekten tedirgin oluyorum" gibi sorulardan oluşmuştur. "Gelecekte, işimle ilgili en önemli hedeflerimi gerçekleştireceğime eminim" ve "inanıyorum ki, Covid-19'a çok yakın gelecekte bir çözüm bulunacak" şeklinde iki adet de ters puanlanacak soru içermektedir. $\mathrm{Bu}$ form Likert tipi, öz bildirim ölçeği olarak hazırlanmıştır. Her bir maddeye; 0: "kesinlikle katılmıyorum", 6: "tamamen katılıyorum", olmak üzere 0-6 arası puan verilmektedir. 0-174 arasında puan alınabilmektedir. Elde edilen toplam puan ne kadar fazla ise kişinin gelecek kaygısı da o kadar fazla olarak kabul edilmiştir (Ek 2).

\section{İstatistiksel analiz}

Katılımcılardan elde edilen verilerin değerlendirilmesinde hazır istatistik yazılımı SPSS for Windows 20 (Statistical Package for Social Sciences for Windows 20; Version 13.0; SPSS; Inc., Chicago, IL) kullanılmıştır. Katılımcıların genel özellikleri hakkında bilgi vermek amacı ile tanımlayıcı analizler; frekans, yüzde dağılımı, ortalama \pm standart sapma yapılmıştır. Sürekli değişkenlere ait veriler ortalama sstandart sapma şeklinde; kategorik değişkenlere ilişkin veriler ise $n(\%)$ şeklinde verilmektedir.

Çalışmanın nitel değişkenleri; cinsiyet, yaş, eğitim durumu, sosyoekonomik durum gibi demografik veriler ile kaç yıldır diş hekimi olarak çalıştığı, sigara ve/veya alkol alımı ve ek tıbbi hastalığının olup olmadığı ve klinik değerlendirme sorularının değerlendirilmesi ile elde edilen sonuçlardır. Nicel değişkenler ise; katılımcılara uygulanan ASÖ'den elde edilen puanlardır. Nitel değişkenler arasında ilişki olup olmadığını değerlendirmek için çapraz tablo ve Ki-kare testlerinden yararlanılmıştır.

\section{Bulgular}

Çalışmamıza 228 katılımcı dahil edildi. 118 kişi (\%52) kadın ve 110 kişi (\%48) erkek idi. Bu kişilerden 77 kişi (\%33,77) 25-35 yaş aralığında, 74 kişi $(\% 32,40)$ 35-45 yaş aralığında, 55 kişi $(\% 24,12) 45-55$ yaş aralığında ve 22 kişi $(\% 9,64)$ 55-65 yaşa aralığında idi. 151 kişi $(\% 66,22)$ evli 
iken 53 kişi $(\% 23,24)$ bekardı. Katılımcılardan 202 kişinin $(\% 88,59)$ bir uzmanlık alanı yoktu. 86 kişi $(\% 37,71)$ kendisine ait muayenehanede çalışıyordu. Meslekte geçirdikleri yıllar ise; 0-5 yıl arası 38 kişi $(\% 16,66), 5-10$ yıl arasında 30 kişi (\%13,15), 10-15 yıl arası 42 kişi $(\% 18,42)$, 15 yıldan fazla ise 118 kişi $(\% 51,75)$ idi. Katılımcılara ait demografik veriler Tablo 1'de sunulmuştur.

Tablo 1. Katılımcıların demografik özellikleri

\begin{tabular}{lcc}
\hline & $\mathbf{n}$ & $\%$ \\
\hline Yaş aralığı & 77 & 33,77 \\
$25-35$ & 74 & 32,40 \\
$35-45$ & 55 & 24,12 \\
$45-55$ & 22 & 9,64 \\
$55-65$ & & \\
Medeni durum & 151 & 66,22 \\
Evli & 53 & 23,24 \\
Bekar & 24 & 10,52 \\
Eşinden ayrılmış & & \\
Çalıştığı kurum & 86 & 37,71 \\
Kendisine ait muayenehane & 69 & 30,26 \\
Kamu hastanesi & 32 & 14,03 \\
Kendi kliniğinde & 23 & 10,08 \\
Diş hekimliği polikliniğinde & 8 & 3,50 \\
Özel hastane & & \\
Uzmanlık alanı & $26 / 202$ & $11,40 / 88,59$ \\
Var/yok & & \\
CovıD-19 nedeni ile işine ara & $62 / 166$ & $27,19 / 72,80$ \\
Verilmiş/verilmemiş & & \\
\hline
\end{tabular}

Hiçbir katııımcının medikal tedavi almasını gerektirir psikiyatrik hastalığı yoktu.

Nicel değişkenlerin analizi Tablo 2'de verilmiştir. Tüm katılımcıların bir arada değerlendirilmesinde ASÖ için elde edilen puan $40,92 \pm 8,68$ olmuştur. Kadınların elde ettiği skorları erkeklerden fazla olmuştur $(p=0,000)$. Gelecek kaygısının değerlendirildiği formdan ise tüm katılımcıların ortak hesaplanmasında $114,18 \pm 33,19$ puan elde edilirken, yine kadınların puanları erkeklerden yüksek olarak saptanmıştır $(p=0,000)$. Diş hekimlerinin yaşı ile uygulanan ölçekler arasında ilişki tespit edilmemiştir $(p>0,05)$. Benzer şekilde diş hekimlerinin çalışma yılı ile algılanan stres ölçeği arasında ilişki yok iken; gelecek kaygısı formu ve çalışma yılı arasında ilişki olduğu görülmüştür.
0-5 yıl arasında diş hekimliği yapanların gelecek kaygıları daha uzun süre çalışan hekimlerden fazla olmuştur $(p=0,036)$. Diş hekimlerinin çalıştıkları kurum/kuruluş ile yaşadıkları stres ve gelecek kaygıları düzeyleri arasında ise anlamlı bir ilişki tespit edilmemiştir. Gelecek kaygısı formunda ters puanlanan sorulardan "gelecekte, işimle ilgili en önemli hedeflerimi gerçekleştireceğime eminim" sorusundan katııımcılar $3,24 \pm 1,71$ puan alınmıştır. Bir diğer ters hesaplanan "inanıyorum ki, COVID-19'a çok yakın gelecekte bir çözüm bulunacak" sorusundan ise $4,19 \pm 1,55$ puan elde edilmiştir. 
Tablo 2. Katılımcıların nicel değişkenlerinin dağılımı

\begin{tabular}{|c|c|c|c|c|c|c|}
\hline & $\begin{array}{l}\text { Algılanan } \\
\text { stres ölçeği }\end{array}$ & $\begin{array}{l}\mathbf{f} \\
\text { değeri }\end{array}$ & $\begin{array}{l}p \\
\text { değeri }\end{array}$ & $\begin{array}{l}\text { Gelecek kaygısı } \\
\text { değerlendirme } \\
\text { formu }\end{array}$ & $\begin{array}{l}\text { f } \\
\text { değeri }\end{array}$ & $\begin{array}{l}p \\
\text { değeri }\end{array}$ \\
\hline $\begin{array}{l}\text { Tüm katılımcılar } \\
\text { (228 diş hekimi) }\end{array}$ & $40,92 \pm 8,68$ & - & - & $114,18 \pm 33,19$ & - & - \\
\hline Kadın & $42,96 \pm 7,93$ & 3,112 & 0,000 & $124,12 \pm 29,85$ & 4,031 & 0,000 \\
\hline Erkek & $38,74 \pm 8,99$ & & & $103,52 \pm 33,56$ & & \\
\hline Çalışmaya ara veren & $40,25 \pm 8,85$ & 0,203 & 0,062 & $112,52 \pm 32,60$ & 0,000 & 0,233 \\
\hline $\begin{array}{l}\text { Çalışmaya devam } \\
\text { eden }\end{array}$ & $42,63 \pm 8,04$ & & & $118,35 \pm 32,60$ & & \\
\hline Evli & $41,26 \pm 7,74$ & 0,212 & 0,095 & $117,60 \pm 34,10$ & 0,000 & 0,290 \\
\hline Bekar & $40,66 \pm 8,85$ & & & $116,50 \pm 33,12$ & & \\
\hline Çocuğu var & $41,06 \pm 7,95$ & 3,531 & 0,761 & $112,28 \pm 33,20$ & 0,001 & 0,250 \\
\hline Çocuğu yok & $40,69 \pm 9,94$ & & & $117,57 \pm 33,31$ & & \\
\hline
\end{tabular}

\section{Tartışma}

Çalışmamızın bulguları hipotezimizle uyumlu olarak diş hekimlerinin COVID-19 döneminde yüksek düzey stres algıladıkları orta düzeyde gelecek kaygısına sahip olduklarını ortaya koymuştur. Çalışmaya katılan diş hekimlerinin salgın öncesi stres ve gelecek kaygısı durumları bilinmediği için bu artışın ne boyutta olduğu araştırılamamıştır. $\mathrm{Bu}$ durum çalışmamızı sınırlayan temel faktördür. Bulgularımız, kadın diş hekimlerinin veya pandemi sürecinde çalışmaya devam eden diş hekimlerinin stres ve gelecek kaygısının daha fazla olduğunu ortaya koymuştur. Öte yandan çalışılan kurum/ kuruluşun stres ya da gelecek kaygısı üzerine anlamlı bir etkisi görülmemiştir.

COVID-19 salgını her geçen gün vaka sayıları ve ölüm oranlarının artması ile savaş ile karşılaştırılabilir bir kriz durumuna gelmiştir. Bu kriz sağlık çalışanları üzerinde hem fiziksel hem de psikolojik baskı oluşturmaktadır [19]. İçinde COVID-19'unda bulunduğu salgın dönemlerinin sağlık personelinin moralini bozup yoğun strese neden olduğu gösterilmiştir [20]. Hemşirelerde COVID-19 salgın sürecinde yapılan bir çalışmada personelin stres düzeylerinin yüksek olduğu tespit edilmiştir. Ayrıca haftada 35 saatin üstünde, genel durumu kötü hastalarla çalışan ve çocuğu olan hemşirelerin stres düzeylerinin daha fazla olduğu da bildirilmiştir
[21]. Hemşire ve doktorlar ile yapılan başka bir çalışmada; katılımcıların stres düzeylerinin yüksek olduğu saptanmıştır. Ek olarak stres düzeylerinin uyku kalitesi ile ters ilişkili olduğu da gösterilmiştir [22]. Henüz sahada çalışmaya başlamamış tıp fakültesi öğrencilerinin de kaygı ve stres düzeylerinin salgın döneminde arttığı saptanmıştır [23]. Ülkemizde diş hekimliği öğrencilerinde yapılan bir çalışmada; öğrencilerin salgın sürecinde kaygı düzeylerinin yükseldiği tespit edilmiştir [16]. Yine ülkemizde tıp fakültesi öğrencilerinde yürütülen bir çalışmada ise; öğrencilerin salgın hakkında sosyal medya aracılığı ile bilgi edindikleri ve bilgilerini yetersiz olarak algıladıkları saptanmıştır. Ek olarak salgının ne zaman ve nasıl sonlanacağı ile ilgili de yoğun bir endişe içinde oldukları tespit edilmiştir [24]. Farklı ülkelerde çalışan diş hekimlerinde COVID-19 salgının oluşturduğu stres ve sübjektif olarak hissettikleri öznel yük düzeylerinin incelendiği çalışmada; ülkeler arası farklılık olduğu saptanmıştır. İngiltere, İtalya ve Çin'de çalışan diş hekimlerinin stres düzeylerinin daha yüksek olduğu bildirilmiştir [25]. Bizim çalışmamızda da bu çalışmalara benzer şekilde diş hekimlerinin stres düzeylerinin yüksek olduğu görüldü. Çalışmamızda diş hekimlerinin çalıştıkları alan ve bulaş riskinin yüksekliği ile stres düzeylerinin yükselmesi kurduğumuz hipotez doğrultusunda beklediğimiz bir snuç olmuştur. 
Literatürde COVID-19 döneminde sağlık çalışanlarının kaygı düzeylerinin yüksek olduğu ve gelecek kaygısı yaşadıkları gösterilmiştir [26-30]. Sağlık çalışanlarında yürütülen bir çalışmada; katılımcıların \%20,1 oran ile kaygı ölçeği için kesme puanını geçtiği hesaplanmıştır [26]. Henüz sahada çalışmaya başlamamış tıp fakültesi öğrencileri ile yapılan bir çalışmada; katıımcıların kaygı değerlendirme aracından aldıkları puan ortalaması 55,3 \pm 14 ,2 olarak hesap edilmiştir [27]. Bir meta analiz çalışmasında; 12 ayrı çalışmada sağlık çalışanlarında kaygı semptomlarının ortalama \%23,21 oran ile görüldüğü saptanmıştır [28]. Diş hekimlerinde yapılan bir çalışmada; hekimlerin COVID-19 hastalığını kapmaktan korktukları hem kendilerine hem de hastalarına bulaş riskinden dolayı kaygı içinde oldukları bildirilmiştir [29]. İçinde diş hekimlerinin de bulunduğu sağlık çalışanlarında yürütülen bir çalışmada; kaygı düzeyleri en yüksek grup hemşireler olarak saptanmıştır. İkinci sırada ise diş hekimleri yer almıştır [30]. Bizim sonuçlarımızda; literatür ile benzer ve hipotezimizi doğrular şekilde diş hekimlerinin gelecek ile ilgili kaygılarının olduğu tespit edildi.

Literatürde yapılan çalışmalarda katılımcıların kaygı düzeylerinin cinsiyetler arasında farklılık gösterdiği bulunmuştur. Kadınların yaşadığı kaygının erkeklerden fazla olduğu gösterilmiştir [13, 15, 28]. Benzer şekilde sonuçlarımızda kadınların hem stres düzeyleri hem de gelecek kaygıları erkeklerden fazla idi. Bazı çalışmalarda sağlık çalışanlarında da kaygı düzeylerinin farklılık gösterdiği bildirilmiştir. Yapılan bir çalışmada hemşirelerde doktorlara göre daha yoğun bir kaygı yaşandığı saptanmıştır [31]. Başka bir çalışmada yine hemşireler kaygı düzeyi en yüksek grup iken diş hekimleri ikinci sırada yer almıştır [30]. Çalışmamızda sadece diş hekimleri olduğu için karşılaştırma yapılamamıştır. Literatürde ileri yaş ve kronik hastalığı olan sağlıkçıların kaygı ve stres düzeyleri daha yüksek bulunan çalışmalar yapılmıştır [31, 32]. Tersi olarak genç yaşta daha yüksek düzeyde kaygı ve stres bildiren çalışmalarda bulunmaktadır [26]. Bazı çalışmalarda ise yaş ve cinsiyetten bağımsız kaygı ve stres bildirilmiştir. Tıbbi ekipman yetersizliği, çalışma koşullarının sağlık çalışanlarında strese ve kaygıya neden olduğu gösterilmiştir [33]. Son olarak sahada ön planda çalışan sağlıkçıların daha fazla kaygı ve stres yaşadığı gösterilmiştir [15]. Bizim sonuçlarımızda ise çalışılan yer ile ne kaygı ne de stres düzeyleri arasında ilişki saptanmamıştır. Sadece meslekte ilk beş yıllarının içinde olan diş hekimlerinde gelecek kaygısının daha fazla olduğu görülmüştür.

Sonuçlarımız bazı kısıtılıklar göz önüne alınarak değerlendirilmelidir. Bu kısıtlılıklardan ilki; çalışmanın kesitsel nitelikte olmasıdır. Diğer kısıtlılıklar; örneklem sayımızın görece yetersiz sayıda oluşu ve öz bildirim ölçekleri ile kişilerin değerlendirilmesi sayılabilir. Bu durum elde ettiğimiz sonuçların genellemesi ve yorumlanmasını sınırlamaktadır. Elde etiğimiz bulguların önem kazanabilmesi için daha büyük örneklem gruplarında daha ileri araştırmalar yapılmasına gerek vardır.

Sonuç olarak, COVID-19 salgını tüm dünya genelinde etkisini yalnızca yüksek ölüm oranı ile değil aynı zamanda artan ikincil psikiyatrik rahatsızlıklarla da gösterdi [34]. Çalışmamızda bu rahatsızlıklar arasında ön sırada yer alan kaygı ve stres düzeylerinin [35] COVID-19 sürecinde diş hekimlerindeki etkisini inceledik. Sonuçlarımız; çapraz enfeksiyonla mücadele etmek konusunda yetkin olan dişhekimlerinin, bulaş oranı çok yüksek bir hastalıkla karşı karşıya kaldıklarında kaygı ve stres düzeylerinin oldukça arttığını ortaya koymaktadır. Bu nedenle pek çok ülkede uygulanmaya başlanmış ya da hazırlıkları yapılan sağlık çalışanlarını [36-38] korumaya yönelik sistemlerin bir an önce hayata geçirilmesinin sağlık hizmetlerinin uygun olarak yapılabilmesi için önemli ve zorunlu olduğunu düşünmekteyiz.

Çıkar ilişkisi: Yazarlar çıkar ilişkisi olmadığını beyan etmişlerdir.

\section{Kaynaklar}

1. She J, Jiang J, Ye L, Hu L, Bai C, Song Y. 2019 novel coronavirus of pneumonia in Wuhan, China: emerging attack and management strategies. Clin Transl Med 2020;9:1-7. https://doi.org/10.1186/s40169-02000271-z

2. Paules $\mathrm{Cl}$, Marston HD, Fauci AS. Coronavirus infections-more than just the common cold. JAMA 2020;323:707-708. https://doi.org/10.1001/ jama.2020.0757 
3. Sohrabi C, Alsafi Z, O'Neill N, et al. World Health Organization declares global emergency: a review of the 2019 novel coronavirus (COVID-19). Int J Surg 2020;76:71-76. https://doi.org/10.1016/j. ijsu.2020.02.034

4. World Health Organization. Novel Coronavirus (2019nCoV). Situation report-155. 23 June 2020. WHO from national authorities by 10:00 CEST. https:// www.who.int/docs/default-source/coronaviruse/ situation-reports/20200623-covid-19-sitrep-155. pdf?sfvrsn=ca01ebe_2. Accessed June 23, 2020

5. Covıd-19. Sağlık Bakanlığı TS. T.C. Sağık Bakanlığı Korona tablosu. Erişim adresi: https://dosyamerkez. saglik.gov.tr/Eklenti/37851, covid-19-gunluk-durumraporu---29062020pdf.pdf?0\&_tag1=9E9A6C88C9D F728AC54FB8C54FEC8AEA3134F703. Erişim tarihi 29 Haziran 2020

6. Heymann DL, Shindo N. WHO Scientific and technical advisory group for infectious hazards. COVID-19: what is next for public health? Lancet 2020;395:542-545. https://doi.org/10.1016/S0140-6736(20)30374-3

7. Qiu J, Shen B, Zhao M, Wang Z, Xie B, Xu Y. Anationwide survey of psychological distress among Chinese people in the COVID-19 epidemic: implications and policy recommendations. Gen Psych 2020;33:e100213. https://doi.org/10.1136/gpsych-2020-100213

8. Shigemura J, Ursano RJ, Morganstein JC, Kurosawa M, Benedek DM. Public responses to the novel 2019 coronavirus (2019-nCoV) in Japan: mental health consequences and target populations. Psychiatry Clin Neurosci 2020;74:281-282. https://doi.org/10.1111/ pcn. 12988

9. Wang C, Pan R, Wan X, et al. Immediate psychological responses and associated factors during the initial stage of the 2019 coronavirus disease (COVID-19) epidemic among the general population in China. Int J Environ Res Public Health 2020;17:1729. https://doi. org/10.3390/ijerph17051729

10. Khader Y, Al Nsour M, Al Batayneh OB, et al. Dentists' awareness, perception, and attitude regarding COVID-19 and infection control: cross-sectional study among Jordanian dentists. JMIR Public Health and Surveill 2020;6:e18798. https://doi.org/10.2196/18798

11. Fallahi HR, Keyhan SO, Zandian D, Kim SG, Cheshmi B. Being a front-line dentist during the Covid-19 pandemic: a literature review. Maxillofac Plast Reconstr Surg 2020;42:1-9. https://doi.org/10.1186/s40902-02000256-5

12. Biçer I, Çakmak C, Demir H, Kurt ME. Koronavirüs anksiyete ölçeği kısa formu: Türkçe geçerlik ve güvenirlik çalışması. Anadolu Kliniği Tıp Bilimleri Derg 2020;25:216-225. https://doi.org/10.21673/ anadoluklin.731092
13. Özdin S, Bayrak Özdin Ş. Levels and predictors of anxiety, depression and health anxiety during COVID-19 pandemic in Turkish society: the importance of gender. Int J Soc Psychiatry 2020;66:504-511. https://doi.org/10.1177/0020764020927051

14. Lai J, Ma S, Wang Y, et al. Factors associated with mental health outcomes among health care workers exposed to coronavirus disease 2019. JAMA Netw Open 2020;3:e203976. https://doi.org/10.1001/ jamanetworkopen.2020.3976

15. Elbay RY, Kurtulmuş A, Arpacıoğlu S, Karadere E. Depression, anxiety, stress levels of physicians and associated factors in Covid-19 pandemics. Psychiatry Res 2020;290:113130. https://doi.org/10.1016/j. psychres.2020.113130

16. Özdede M, Sahin SC. Views and anxiety levels of Turkish dental students during the COVID-19 pandemic. J Stoma 2020;73:123-128. https://doi. org/10.5114/jos.2020.96867

17. Eskin M, Harlak H, Demirkıran F, Dereboy Ç. Algılanan stres ölçeğinin Türkçe'ye uyarlanması: güvenirlik ve geçerlik analizi. New Symposium J 2013;51:132-140.

18. Zaleski Z. Future anxiety: concept, measurement, and preliminary research. Pers Individ Diff 1996;21:165174. https://doi.org/10.1016/0191-8869(96)00070-0

19. Walton M, Murray E, Christian MD. Mental health care for medical staff and affiliated healthcare workers during the COVID-19 pandemic. Eur Heart J Acute Cardiovasc Care 2020;9:241-247. https://doi. org/10.1177/2048872620922795

20. Imo UO. Burnout and psychiatric morbidity among doctors in the UK: a systematic literature review of prevalence and associated factors. BJ Psych Bull 2017;41:197-204. https://doi.org/10.1192/ pb.bp.116.054247

21. Mo $Y$, Deng $L$, Zhang $L$, et al. Work stress among Chinese nurses to support Wuhan in fighting against COVID-19 epidemic. J Nurs Manag 2020;28:10021009. https://doi.org/10.1111/jonm.13014

22. Xiao $\mathrm{H}$, Zhang $\mathrm{Y}$, Kong D, Li S, Yang $\mathrm{N}$. The effects of social support on sleep quality of medical staff treating patients with coronavirus disease 2019 (COVID-19) in January and February 2020 in China. Med Sci Monit 2020;26:e923549. https://doi.org/10.12659/ MSM.923549

23. Sartorao Filho $\mathrm{Cl}$, Rodrigues WCDLV, de Castro RB, et al. Impact of Covid-19 pandemic on mental health of medical students: a cross-sectional study using GAD-7 and PHQ-9 questionnaires. JMIR Preprints 2020:1-13. https://doi.org/10.1101/2020.06.24.20138925

24. Aker S, Mıdık O. The views of medical faculty students in Turkey concerning the COVID-19 pandemic. J Comm Health 2020;45:684-688. https://doi.org/10.1007/ s10900-020-00841-9 
25. Mijiritsky E, Hamama Raz Y, Liu F, et al. Subjective overload and psychological distress among dentists during COVID-19. Int J Environ Res Public Health 2020;17:5074. https://doi.org/10.3390/ijerph17145074

26. Liang $Y$, Chen $M$, Zheng $X$, Liu J. Screening for Chinese medical staff mental health by SDS and SAS during the outbreak of COVID-19. J Psychosom Res 2020;133:110102. https://doi.org/10.1016/j. jpsychores.2020.110102

27. Lew B, Huen J, Yu P, et al. Associations between depression, anxiety, stress, hopelessness, subjective well-being, coping styles and suicide in Chinese university students. PloS One 2019;14:e0217372. https://doi.org/10.1371/journal.pone.0217372

28. Pappa S, Ntella V, Giannakas T, Giannakoulis VG, Papoutsi E, Katsaounou P. Prevalence of depression, anxiety, and insomnia among healthcare workers during the COVID-19 pandemic: a systematic review and meta-analysis. Brain Behav Immun 2020;88:901907. https://doi.org/10.1016/j.bbi.2020.05.026

29. Ahmed MA, Jouhar $\mathrm{R}$, Ahmed $\mathrm{N}$, et al. Fear and practice modifications among dentists to combat Novel Coronavirus Disease (COVID-19) outbreak. Int J Environ Res Public Health 2020;17:2821. https://doi. org/10.3390/ijerph17082821

30. Saleem Z, Majeed MM, Rafique S, et al. COVID-19 pandemic fear and anxiety among healthcare professionals in Pakistan. Res Square 2020:1-17. https://doi.org/10.21203/rs.3.rs-37608/v2

31. Spoorthy MS, Pratapa SK, Mahant S. Mental health problems faced by healthcare workers due to the COVID-19 pandemic-a review. Asian J Psychiatr 2020;51:102119. https://doi.org/10.1016/j. ajp.2020.102119

32. Hacimusalar Y, Kahve AC, Yasar AB, Aydin MS. Effects of coronavirus disease 2019 (COVID-19) pandemic on anxiety and hopelessness levels: A cross-sectional study in healthcare workers and community sample in Turkey. J Psychiatr Res 2020;129:181-188. https://doi. org/ 10.1016/j.jpsychires.2020.07.024

33. Cai H, Tu B, Ma J, et al. Psychological impact and coping strategies of frontline medical staff in hunan between january and march 2020 during the outbreak of coronavirus disease 2019 (COVID-19) in Hubei, China. Med Sci Monit 2020;26:e924171. https://doi. org/10.12659/MSM.924171

34. Xiao C. A novel approach of consultation on 2019 novel coronavirus (COVID-19)- Related psychological and mental problems: structured letter therapy. Psychiatr Invest 2020;17:175-176. https://doi.org/10.30773/ pi.2020.0047

35. Mak IWC, Chu CM, Pan PC, Yiu MGC, Chan VL. Longterm psychiatric morbidities among SARS survivors. Gen Hosp Psychiatr 2009;31:318-326. https://doi. org/10.1016/j.genhosppsych.2009.03.001
36. Rana W, Mukhtar S, Mukhtar S. Mental health of medical workers in Pakistan during the pandemic COVID-19 outbreak. Asian J Psychiatr 2020;51:102080. https:// doi.org/10.1016/j.ajp.2020.102080

37. Coulthard P. Dentistry and coronavirus (COVID-19) moral decision-making. Br Dent J 2020;228:503-505. https://doi.org/10.1038/s41415-020-1482-1

38. Kılıçarslan MA, Şenel FÇ, Özcan M. Assessment of dental care during the covid-19 pandemic in Turkey and future projections. Braz Dent Sci 2020;23:2. https://doi. org/10.14295/bds.2020.v23i2.2260

Etik kurul onayı: Marmara Üniversitesi Tıp Fakültesi Klinik Araştırmalar Etik Kurulu'nun 06.05.2020 tarih ve 09.2020.472 protokol numarası ile onay alındı.

\section{Yazarların makaleye olan katkıları}

E.B.G. çalışmanın ana fikrini ve hipotezini kurgulamıştır ve teoriyi geliştirmiş ve materyal metot bölümünü düzenlemiştir. Sonuçlar kısmındaki verilerin değerlendirmesini E.B.G., M.K., F.Ö. yapmışlardır. Makale F.Ö. tarafından yazılmış, M.K., E.B.G., D.Ö. gözden geçirip gerekli düzeltmeleri yapmış ve onaylamıştır. Ayrıca tüm yazarlar çalışmanın tamamını tartışmış ve son halini onaylamıştır. 


\section{Ek 1: Algılanan stres ölçeği}

Yönerge: Aşağıda geçtiğimiz ay içerisindeki kişisel deneyimleriniz hakkında bir dizi soru yöneltilmektedir. Her soruyu dikkatlice okuyarak size en uygun seçeneğin altındaki kutuya bir çarpı işareti koyarak cevaplayınız. Soruların doğru veya yanlış cevabı yoktur. Önemli olan sizin duygu ve düşüncelerinizi yansıtan yanıtları vermenizdir.

\begin{tabular}{|c|c|c|c|c|c|}
\hline & $\begin{array}{l}\text { Hiçbir } \\
\text { Zaman }\end{array}$ & $\begin{array}{l}\text { Neredeyse } \\
\text { Hiçbir Zaman }\end{array}$ & Bazen & $\begin{array}{l}\text { Oldukça } \\
\text { Sık }\end{array}$ & $\begin{array}{l}\text { Çok } \\
\text { sık }\end{array}$ \\
\hline \multicolumn{6}{|l|}{ kontrol edemediğinizi ne sıklıkta hissettiniz? } \\
\hline \multicolumn{6}{|l|}{$\begin{array}{l}\text { 3. Geçen ay, kendinizi ne sıklıkta sinirli ve stresli } \\
\text { hissettiniz? }\end{array}$} \\
\hline \multicolumn{6}{|l|}{$\begin{array}{l}\text { 4. Geçen ay ne sıklıktya gündelik zorlukların üste- } \\
\text { sinden geldiniz? }\end{array}$} \\
\hline \multicolumn{6}{|l|}{ 6. Geçen ay, kişisel sorunlarınızı ele alma } \\
\hline \multicolumn{6}{|l|}{ yeteneğinize ne sıklıkta güven duydunuz? } \\
\hline \multicolumn{6}{|l|}{$\begin{array}{l}\text { 7. Geçen ay, her şeyin yolunda gittiğini ne sıklıkta } \\
\text { hissettiniz? }\end{array}$} \\
\hline \multicolumn{6}{|l|}{ 8. Geçen ay, ne sıklıkta yapmanız gereken } \\
\hline \multicolumn{6}{|l|}{ şeylerle başa çıkamadığınızı fark ettiniz? } \\
\hline \multicolumn{6}{|l|}{ 10. Geçen ay, ne sıklıkta her şeyin üstesinden } \\
\hline \multicolumn{6}{|l|}{ geldiğinizi hissettiniz? } \\
\hline \multicolumn{6}{|l|}{ 11. Geçen ay, ne sıklıkta kontrolünüz dışında } \\
\hline \multicolumn{6}{|l|}{ gelişen olaylar yüzünden öfkelendiniz? } \\
\hline \multicolumn{6}{|l|}{$\begin{array}{l}\text { 12. Geçen ay kendinizi ne sıklıkta başarmak zorun- } \\
\text { da olduğunuz şeyleri düşünürken buldunuz? }\end{array}$} \\
\hline \multicolumn{6}{|l|}{$\begin{array}{l}\text { 13. Geçen ay ne sıklıkta zamanınızı nasıl kullana- } \\
\text { cağınızı kontrol edebildiniz? }\end{array}$} \\
\hline $\begin{array}{l}\text { 14. Geçen ay, ne sıklıkta problemlerin üstesinden } \\
\text { gelemeyeceğiniz kadar biriktiğini hissettiniz? }\end{array}$ & & & & & \\
\hline
\end{tabular}




\section{Ek 2: Gelecek Kaygısı Formu}

1. Yarın çalışmak zorunda kalırsam kendimi çok kötü hissederim

2. Geleceğim çok belirsiz.

3. Korkarım yakında bazı felaketler gerçekleşecek.

4. Ertesi gün, ay ne getirecek düşündüğümde korkuyorum.

5. Gelecekle ilgili plan yapmakta korkuyorum

6. Olası aksilikler hakkında tedirginim.

7. Hastalarla ilgili ortaya çıkacak sorunların üzerinden gelememekten korkuyorum.

8. Bir hastayı COVID-19 ile kontamine etmekten korkuyorum.

9. Bir hasta tarafından COVID-19 ile enfekte edilmekten korkuyorum.

10. Hastaları görürken oluşabilecek sorunlar hakkında çok endişeleniyorum.

11. Bir hastayı görürken bazen hayatın krizleri veya zorluklarıyla karşılaşabileceğim düşüncesinden korkuyorum

12. Klinikteki gelecekteki işlerimi düşündüğümde gerginlik ve tedirginlik durumuna düşüyorum

13. Gelecekte, işimle ilgili en önemli hedeflerimi gerçekleştireceğime eminim.

14. Hastalarımı Covid-19'dan korumak için uygun şartlar sağlayamayacak olmaktan endişeliyim.

15. Dünyanın kıyamete doğru sürüklendiği hissine kapıldım.

16. Hayatımda vermiş olduğum karar ve eylemlerin hesabını vereceğim anın gelmesinden korkuyorum.

17. Ölüme korktuğumdan daha yakınım.

18. İnanıyorum ki, Covid-19'a çok yakın gelecekte bir çözüm bulunacak

19. Ekonomik-politikal durumdaki değişiklikler korkarım geleceğimi tehdit edecek.

20. Hayatın hızla geçtiği düşüncesi beni korkutuyor

21. Yakın gelecekte korkarım işimle ilgili planladığım hedeflere Covid-19 nedeniyle ulaşamayacağım.

22. Covid-19 nedeniyle işimde şu an karşı karşıya olduğum sorunlar korkarım daha uzun süre devam edecek.

23. Covid-19 bulaşma intimali beni rahatsız ediyor.

24. Covid-19'lu hastaları görsem bile takdir göreceğimi düşünmüyorum.

25. Korkarım devlet bizim mesleğimizi takdir etmiyor, bizi yalnız bıraktı.

26. Korkarım, devlet Covid-19 süresince diş sağlığını umursamıyor. 